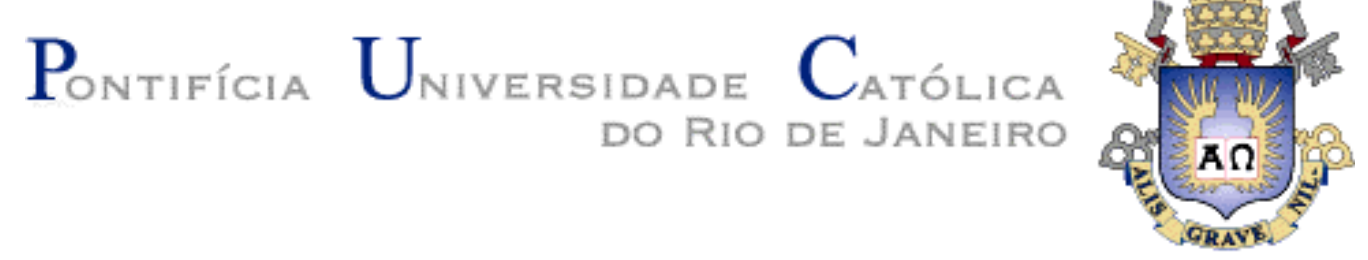

João Fabio Franco Ferreira

\title{
Apreçamento de Opções de Futuro de DI utilizando o modelo HJM
}

\section{Dissertação de Mestrado}

Dissertação apresentada ao Programa de Pósgraduação em Administração de Empresas da PUCRio como requisito parcial para obtenção do título de Mestre em Administração de Empresas

Orientador: Prof. Antonio Carlos Figueiredo Pinto

Rio de Janeiro

Agosto de 2011 


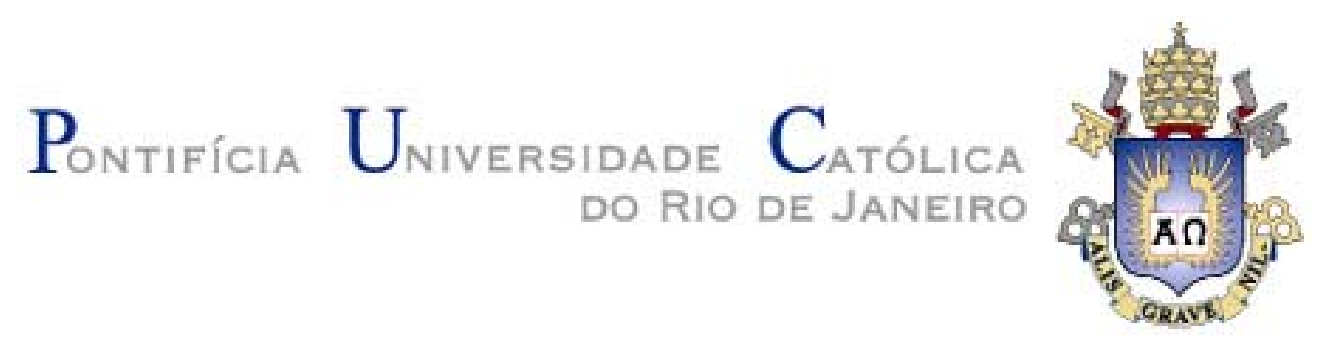

João Fabio Franco Ferreira

\title{
Apreçamento de Opções de Futuro de DI utilizando o modelo HJM
}

Dissertação apresentada como requisito parcial para obtenção do grau de Mestre pelo Programa de Pósgraduação em Administração de Empresas da PUC-Rio. Aprovada pela Comissão Examinadora abaixo assinada.

\author{
Prof. Antonio Carlos Figueiredo Pinto \\ Orientador \\ Departamento de Administração - PUC-Rio
}

Prof. Marcelo Cabus Klotzle Departamento de Administração - PUC-Rio

Prof. Marco Antonio Cunha de Oliveira

FACC - UFRJ

Profa. Mônica Herz

Vice-Decana de Pós-Graduação do CCS

Rio de Janeiro, 26 de agosto de 2011 
Todos os direitos reservados. É proibida a reprodução total ou parcial do trabalho sem autorização do autor, do orientador e da universidade.

\section{João Fabio Franco Ferreira}

Possui Graduação em Ciências Econômicas pelo Instituto Brasileiro de Mercado de Capitais - IBMEC RJ (2005), bem como Graduação em Administração pela Universidade Federal do Rio de Janeiro - UFRJ (2006). É economista do Banco Nacional de Desenvolvimento Econômico e Social - BNDES.

Ficha Catalográfica

Ferreira, João Fabio Franco

Apreçamento de opções de futuro de DI utilizando o modelo HJM / João Fabio Franco Ferreira ; orientador: Antonio Carlos Figueiredo Pinto. - 2011. 34 f. : il. (color.) ; $30 \mathrm{~cm}$

Dissertação (mestrado)-Pontifícia Universidade Católica do Rio de Janeiro, Departamento de Administração, 2011.

Inclui bibliografia

1. Administração - Teses. 2. HJM. 3. Opções de futuro de DI. 4. Estrutura a termo da taxa de juros. I. Pinto, Antonio Carlos Figueiredo. II. Pontifícia Universidade Católica do Rio de Janeiro. Departamento de Administração. III. Título. 


\section{Agradecimentos}

A Deus que me protege e ilumina em todos os momentos de minha vida.

A minha querida e amada família que está sempre presente me dando apoio e carinho.

Ao Professor Antonio Carlos Figueiredo Pinto, meu orientador, por toda assistência e dedicação para comigo durante a elaboração desta dissertação de mestrado.

Aos professores que participaram da Comissão Examinadora.

A todos os professores e funcionários do Departamento. 


\section{Resumo}

Ferreira, João Fabio Franco; Pinto, Antonio Carlos Figueiredo. Apreçamento de Opções de Futuro de DI utilizando o modelo HJM. Rio de Janeiro, 2010. 34p. Dissertação de Mestrado - Departamento de Administração, Pontifícia Universidade Católica do Rio de Janeiro.

O objetivo deste trabalho é comparar, pela primeira vez, o apreçamento de opções de futuro de DI de um dia através do modelo HJM de um fator e volatilidade constante, no formato do caso particular Ho-Lee, com os prêmios de referência divulgados pela BM\&FBovespa, que atualmente utiliza o modelo de Black. De outubro de 2009 a abril de 2011 foram avaliadas as quatro principais séries de opções do tipo 2 (cujo futuro objeto possui vencimento seis meses após o vencimento da opção), coletando os prêmios de referência, com base semanal, para todos os exercícios divulgados pela BM\&FBovespa por um período de nove meses anteriores ao vencimento de cada opção. Ainda que tenham sido verificados poucos resultados estatisticamente significativos, foi possível inferir que não só a BM\&FBovespa super-apreça as opções, mas que também existe uma relação negativa entre o apreçamento dos modelos frente à proximidade do dinheiro.

\section{Palavras-chave}

HJM; opções de futuro de DI; estrutura a termo da taxa de juros. 


\section{Abstract}

Ferreira, João Fabio Franco; Pinto, Antonio Carlos Figueiredo (Advisor). Pricing DI future options using the HJM model. Rio de Janeiro, 2011. 34p. MSc. Dissertation - Departamento de Administração, Pontifícia Universidade Católica do Rio de Janeiro.

The goal of this paper is to compare for the first time the DI future option pricing throught the HJM model with one factor and constant volatility, in the special case format of Ho-Lee, with the option reference premium released by BM\&FBovespa, which uses the Black model nowadays. From October 2009 until April 2011 was studied the four main type 2 option series (which the underlying future expires six months after the option expiration date) were analysed, collecting option reference premium data, in weekly basis, for all strikes released by BM\&FBovespa in a nine month period prior to the option expiration date. Even though it was verified few results statistically significant, it was possible to infer that not only the BM\&FBovespa overprices the options but also there is a negative relation with moneyness between the pricing of the models.

\section{Keywords}

HJM; DI future option, interest rate term structure. 


\section{Sumário}

$\begin{array}{ll}\text { 1. Introdução } & 9\end{array}$

2. Referencial Teórico 14

2.1. Modelo de Black 14

2.2. Principais Modelos de Equilíbrio Geral 15

2.2.1. Modelo de Vasicek 15

2.2.2. Modelo CIR 16

2.3. Principais Modelos de Não-Arbitragem 17

$\begin{array}{ll}\text { 2.3.1. Modelo Ho-Lee } & 17\end{array}$

$\begin{array}{ll}\text { 2.3.2. Modelo Hull-White } & 18\end{array}$

2.3.3. Modelo Black-Derman-Toy 18

2.3.4. Modelo HJM 19

3. Especificações da Opção de Futuro de DI 21

3.1. Ativo Objeto 21

3.2. Tipo de Opção 22

3.3. Séries de Vencimento 22

3.4. Exercício 23

4. Metodologia $\quad 24$

4.1. Objetivo da Análise $\quad 24$

4.2. Levantamento de Dados 24

4.3. Implementação do Modelo 25

5. Resultados 26

5.1. Resultado da Call de Taxa (Put de PU) N10/F11 26

5.2. Resultado da Call de Taxa (Put de PU) N11/F12 27

5.3. Resultado da Put de Taxa (Call de PU) N10/F11 28

5.4. Resultado da Put de Taxa (Call de PU) N11/F12 28

6. Conclusão 30

7. Referências Bibliográficas 32 


\section{Lista de tabelas}

Tabela 1 - Apresentação das Séries de Opções Analisadas 25

Tabela 2 - Resultado das opções Call de Taxa (Put de PU) N10/F11.

Tabela 3 - Resultado das opções Call Taxa (Put de PU) N11/F12

Tabela 4 - Resultado das opções Put de Taxa (Call de PU) N10/F11

Tabela 5 - Resultado das opções Put de Taxa (Call de PU) N11/F12 